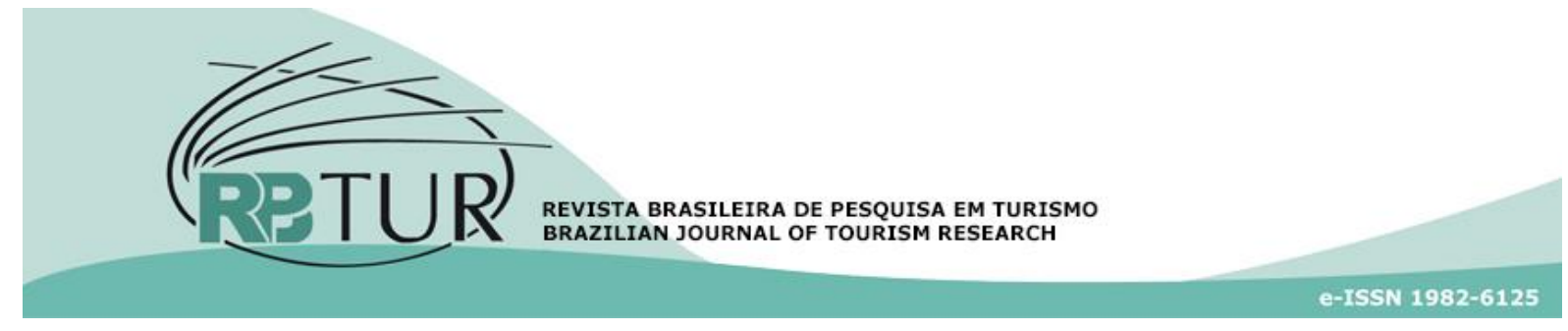

Artigo

DOI: http://dx.doi.org/10.7784/rbtur.v11i2.1286

\title{
Panorama da visitação e da condução de visitantes em Parques brasileiros
}

\section{View of visitation and guiding visitors in Brazilian Parks}

\section{Panorama de las visitas y conducción de visitantes en Parques brasileños}

\section{Celson Roberto Canto-Silva ${ }^{1}$ Jordana Santos da Silva²}

Resumo: Propósito do tema: O uso público em Unidades de Conservação (UCs), principalmente através da visitação, pode trazer benefícios diretos e indiretos à sociedade. Os Parques constituem-se em áreas muito favoráveis à visitação, podendo proporcionar aos visitantes a oportunidade de conhecer, entender e valorizar os recursos naturais e culturais existentes nessas áreas e contribuir com o desenvolvimento socioeconômico local. O conhecimento do panorama em que se dá a visitação nos Parques brasileiros, assim como da condução de visitantes, importante atividade no ordenamento dessa visitação, é de fundamental importância para a gestão do uso público crescente nessas áreas e para a avaliação do impacto da atividade nas comunidades locais. Objetivo: O presente trabalho objetivou, através de uma pesquisa documental e do levantamento de informações junto aos gestores das UCs, contribuir com informações sobre a visitação atual nos Parques brasileiros e sobre a condução de visitantes nessas áreas. Metodologia e abordagem: A pesquisa documental foi baseada nos dados do Cadastro Nacional de Unidades de Conservação (CNUC) e as informações junto aos gestores foram obtidas através de questionário elaborado e enviado a estes através da ferramenta Google.docs. Resultados: Com base no CNUC, apenas 33,42\% dos Parques estão abertos à visitação. O maior percentual de unidades abertas à visitação é observado entre os parques geridos pela esfera federal $(45,07 \%)$ ou municipal (44,55\%), assim como entre aqueles localizados nos biomas Caatinga $(40,00 \%)$ ou Mata Atlântica (38,91\%). Em relação às informações fornecidas pelos gestores dos Parques, evidencia-se que o número anual de visitantes predominante nestes é superior a 10.000 (46,88\%), que os condutores locais atuam de forma exclusiva em $52,13 \%$, estando presentes em $81,25 \%$ deles, e que em $39,06 \%$ das áreas a atuação dos condutores de visitantes é feita de forma associativada. Originalidade: Apesar do incremento do número de visitantes, a proporção de

${ }^{1}$ Instituto Federal de Educação, Ciência e Tecnologia do Rio Grande do Sul (IFRS). Porto Alegre, RS, Brasil. Concepção e desenho do trabalho científico; Análise e interpretação dos dados; Redação e revisão crítica do trabalho; Preparação do artigo científico e Revisão Final.

${ }^{2}$ Instituto Federal de Educação, Ciência e Tecnologia do Rio Grande do Sul (IFRS). Porto Alegre, RS, Brasil. Coleta de dados; Redação do trabalho e Preparação do artigo científico.

Artigo recebido em: 22/02/2017. Artigo aceito em: 30/04/2017

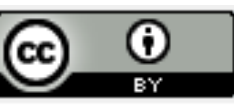


Parques com visitação, pelo menos no que diz respeito aos Nacionais e Estaduais, não se alterou nos últimos 10 anos. Os condutores locais têm um papel protagonista na condução de visitantes nos Parques brasileiros. A atuação coletiva dos prestadores de serviço de condução de visitantes é uma realidade em pouco mais de um terço dessas áreas.

Palavras-chave: Visitação. Unidades de Conservação. Parques. Condutores de visitantes.

Abstract: Proposal: Public use in Conservation Units (UCS), mainly through visitation, can bring direct and indirect benefits to society. The Parks constitute areas very favorable to visitation and can provide visitors with the opportunity to know, understand and value the natural and cultural resources in these areas and contribute to socioeconomic development local. Knowledge of the panorama in which this visitation takes place in the Brazilian parks, as well as of the conduction of visitors, important activity in the planning of this visitation, is of fundamental importance for the management of the increasing public use in these areas and for the evaluation of the impact of the activity in the local communities. Objective: The present work aimed, through a documentary research and the gathering of information with the managers of the PAs, to contribute with information on the current visitation in the Brazilian Parks and on the conduction of visitors in these areas. Methodological Design: The research was based on data from the National Register of Conservation Units (CNUC) and the information of the managers was obtained through a questionnaire elaborated and sent to them through the Google.docs tool. Results: Based on the CNUC, only 33.42\% of the Parks are open to visitation. The highest percentage of units open to visitation is observed among the parks managed by the federal sphere (45.07\%) or municipal (44.55\%), as well as those located in the Caatinga (40.00\%) or Atlantic Forest (38, 91\%). Regarding the information provided by the managers of the Parks, it is evident that the number of visitors per year is more than 10,000 (46.88\%), that the local guiding act exclusively in $52.13 \%$, being present in $81,25 \%$ of them, and that in $39.06 \%$ of the areas the activity of the drivers of visitors is done in an associative way. Originality: In spite of the increase in the number of visitors, the proportion of Parks with visitation, at least with regard to National and State, has not changed in the last 10 years. The Local guiding has a leading role in guiding visitors to Brazilian Parks. The collective performance of the guiding visitors is a reality in a little more than one third of these areas.

Keywords: Visitation. Protected Areas. Parks. Guiding visitors.

Resumen: Finalidad tema: El uso público en áreas protegidas (APS), especialmente a través de las visitas, puede aportar beneficios directos e indirectos para la sociedade. Parques están en muy favorable para visitacion y puede ofrecer a los visitantes la oportunidad de aprender, comprender y valorar los recursos naturales y culturales existentes en estas áreas y contribuir al desarrollo socioeconómico local. El conocimiento del panorama que se da a esta visita en los parques de Brasil, así como de la conducción de visitantes, actividad importante en la planificación de esta visita es de importancia fundamental para la gestión del uso público cada vez mayor en estas áreas y para evaluar el impacto de la actividad en comunidades locales. Meta: Este estudio tuvo como objetivo, a través de la investigación documental y la encuesta de información con los administradores de áreas protegidas, aportar información sobre la visita actual en Parques brasileños y visitantes acerca de la conducción en estas áreas. Metodología y el enfoque: La investigación documental se basa en el Registro Nacional de Unidades de Conservación (CNUC) e información con los gerentes se obtuvieron mediante un cuestionario preparado y enviado a estos a través de la herramienta Google.docs. Los resultados: Basado en CNUC, sólo el $33,42 \%$ de los parques están abiertos a los visitantes. Se observa el mayor porcentaje de unidades que se pueden visitar entre los parques administrados por el nivel federal (45,07\%) o Municipal (44.55\%), así como los ubicados en la Caatinga (40,00\%) o el Mata Atlántica (38, 91\%). En cuanto a la información proporcionada por los gestores de parques, muestra que el número anual de visitantes predominante en estas es mayor que 10.000 (46,88\%), estando presentes los conductores locales que operan exclusivamente en 52,13\%, en 81 25\% de ellos, y en el 39,06\% de las áreas de las actividades de los conductores de visitantes se hace de manera associativada. La originalidad: A pesar del aumento en el número de visitantes, la relación de los parques para visitar, al menos con respecto a Nacional y el Estado, no ha cambiado en los últimos 10 años. Los conductores locales tienen un papel principal en la conducción de los visitantes en los parques brasileños. El trabajo colectivo de los conductores de visitantes es una realidad en poco más de un tercio de estas áreas. 
Palabras Clave: Visitacion. Unidades de Conservación. Parques. Conductores de Visitantes.

\section{INTRODUÇÃO}

A fauna e a flora, os rios, os mares, as montanhas, cada um dos elementos da natureza tem um papel a desempenhar. $E$ para que isso ocorra é preciso haver equilíbrio. Muitos povos e civilizações reconheceram, ao longo da história, a necessidade de proteger áreas naturais com características especiais, por motivos os mais diversos - estas áreas podiam estar associadas a mitos, fatos históricos marcantes e à proteção de fontes de água, caça, plantas medicinais e outros recursos naturais.

Com o passar do tempo, muitas áreas naturais foram sendo destruídas para dar lugar à ocupação humana. Animais e plantas foram eliminados, alguns desapareceram e outros, até os dias atuais, ainda correm risco de extinção. Foi no final do século XIX, nos Estados Unidos, ainda que motivado apenas pela possibilidade de observação das belezas naturais, que foi criada a primeira área protegida moderna, o Parque Nacional de Yellowstone, em 1872 (Ganem, 2010). A partir desta iniciativa, ao longo do século XX, diversos países do mundo adotaram a mesma estratégia, criando parques nacionais e outras unidades de conservação - inclusive o Brasil.

Em nosso país, que é considerado o mais rico em biodiversidade do mundo (Cutolo, Malheiros \& Philippi Jr., 2010), as iniciativas em prol da conservação são antigas, datando do período do império, e estiveram ligadas a manutenção dos mananciais e da qualidade da água servida. Um exemplo disto foi o replantio de uma parte da Floresta da Tijuca, no Rio de Janeiro, entre 1861 e 1889 (Drummond, Franco \& Oliveira, 2010). No entanto, as primeiras Unidades de Conservação brasileiras surgiram apenas na década de 1930 , sendo a primeira o Parque Nacional de Itatiaia, criado em 1937.

O Sistema Nacional de Unidades de Conservação - SNUC (Lei n. 9.985, 2000), instituído pela Lei no 9.985, de 18 de julho de 2000, representou grande avanço à criação e gestão das UCs nas três esferas de governo (federal, estadual e municipal), pois possibilitou uma visão de conjunto das áreas naturais a serem preservadas. Além disso, estabeleceu mecanismos que regulamentam a participação da sociedade na gestão dessas áreas, potencializando a relação entre o Estado, os cidadãos e o meio ambiente.

De acordo com o SNUC, Unidade de Conservação (UC) é a denominação dada aos:

espaços territoriais e seus recursos ambientais, incluindo as águas jurisdicionais, com características naturais relevantes, legalmente instituídos pelo Poder Público, com objetivos de conservação e limites definidos, sob regime especial de administração (Lei n. 9.985, 2000).

O SNUC organiza as UCs em dois grupos, de acordo com seus objetivos de manejo e tipos de uso: Proteção Integral e Uso Sustentável. As Unidades de Proteção 
Integral têm como principal objetivo preservar a natureza, sendo admitido apenas o uso indireto dos seus recursos naturais, como recreação em contato com a natureza, turismo ecológico, pesquisa científica, educação e interpretação ambiental, entre outras. As Unidades de Uso Sustentável, por sua vez, têm como objetivo compatibilizar a conservação da natureza com o uso sustentável dos recursos, conciliando a presença humana nessas áreas. Nesse grupo, atividades que envolvem coleta e uso dos recursos naturais são permitidas, desde que praticadas de uma forma a manter constantes os recursos ambientais renováveis e os processos ecológicos (Lei n. 9.985, 2000).

Os Parques Nacionais (Parna) são UCs de proteção integral que tem como objetivo básico a preservação de ecossistemas naturais de grande relevância ecológica e beleza cênica, possibilitando a realização de pesquisas científicas e o desenvolvimento de atividades de educação e interpretação ambiental, de recreação em contato com a natureza e de turismo ecológico. As unidades dessa categoria, quando criadas pelo Estado ou Município, são denominadas, respectivamente, Parque Estadual (PE) e Parque Natural Municipal (PNM).

Enquanto UC de proteção integral, admitindo apenas o uso indireto dos seus recursos naturais, os Parques constituem-se em áreas muito favoráveis para a promoção de atividades educativas, de lazer, esportivas, recreativas, científicas e de interpretação ambiental, que proporcionam ao visitante a oportunidade de conhecer, entender e valorizar os recursos naturais e culturais existentes nas áreas protegidas. Uso público é um termo diretamente associado a esse conjunto de atividades nas UCs (MMA, 2005). Segundo a Lei n. 9.985 (2000), tais atividades só podem ser implementadas na UC após a elaboração do seu Plano de Manejo.

\section{O Plano Estratégico Nacional de Áreas} Protegidas (Decreto n. 5.758, 2006), documento que apresentou os princípios e diretrizes que devem nortear as ações a serem desenvolvidas em UCs, apontou que uma das estratégias para o alcance da consolidação do SNUC é o fortalecimento da comunicação, da educação e a sensibilização pública para participação e controle dessas áreas, promovendo o desenvolvimento sustentável e a redução da pobreza. Assim, a difusão do uso público em UCs, principalmente através da sua visitação, é uma das principais estratégias para alcançar tais objetivos, trazendo inúmeros benefícios diretos e indiretos para a sociedade e para a própria gestão territorial dessas áreas (Vallejo, 2013). Além dos benefícios pessoais, relacionados à melhoria da saúde física e mental dos visitantes, o uso público pode promover a valorização desses espaços, reduzindo eventuais conflitos territoriais decorrentes da sua criação. Por outro lado, os recursos auferidos pela visitação trazem para as populações locais benefícios coletivos, como postos de trabalho e aumento da renda.

De acordo com o ICMBio (2016), no período de 2007 a 2015, a visitação anual nos Parques Nacionais aumentou de cerca de 3 milhões de pessoas para aproximadamente 7 milhões. Isto representa um acréscimo muito 
significativo no número de visitantes. Considerando que, em 2015, isto representou quase $90 \%$ dos visitantes em UCs federais, fica evidente a importância dos Parques para o crescimento da visitação nas UCs federais brasileiras.

Medeiros e Young (2011), em estudo sobre o impacto econômico na economia local da visitação em Parques Nacionais e Estaduais brasileiros, estimaram, com base nas tendências atuais de crescimento do fluxo de turistas no país, no aumento do interesse por atividades recreativas em ambientes naturais e nos investimentos direcionados aos parques nacionais nos últimos anos, que este seria da ordem de 2,2 bilhões de reais, valor equivalente a 3,5 vezes os auferidos em 2009. Segundo os autores, tal panorama tem um efeito multiplicador na economia local, uma vez que a prestação de serviços de apoio à visitação em UCs ultrapassa os limites das áreas, refletindo a interdependência existente entre os diversos setores que compõem o arranjo produtivo do turismo.

Dentre os serviços de apoio à visitação em UCs, a atividade de condução de visitantes apresenta um grande potencial para a inserção da comunidade local no arranjo produtivo do turismo, permitindo muitas vezes a transição de ocupações de maior impacto ao ambiente para uma atividade de relevância para a conservação dessas áreas (Pisciotta, 1994; Silveira, 1997). Segundo Ferreira e Coutinho (2010), o condutor de visitantes pode ser o elo entre o meio ambiente natural e cultural da localidade e o visitante, contribuindo decisivamente para o ordenamento e a con- dução da atividade de visitação a atrativos naturais.

Apesar do papel fundamental que a visitação e a condução de visitantes podem apresentar para a sustentabilidade das UCs e para o desenvolvimento das comunidades locais, verifica-se que os dados gerados sobre os temas são ainda incipientes, muitas vezes pontuais e específicos a uma ou outra área protegida. Assim, o presente trabalho ocupase em sistematizar algumas informações atuais referentes à visitação e à condução de visitantes nos Parques, principal destino entre as UCs brasileiras.

\section{VISITAÇÃO EM UNIDADES DE CONSERVA- ÇÃO BRASILEIRAS E A ATIVIDADE DE CON- DUÇÃO DE VISITANTES: ALGUNS MARCOS CONCEITUAIS E LEGAIS}

Passold e Kinker (2010) afirmam que, embora não se tenham dados comprobatórios, há evidências que o crescimento da visitação em UCs brasileiras está relacionado ao incremento do ecoturismo no país. O Ecoturismo é o segmento da atividade turística que utiliza, de forma sustentável, o patrimônio natural e cultural, incentiva sua conservação e busca a formação de uma consciência ambientalista através da interpretação do ambiente, promovendo o bem-estar das populações envolvidas (Brasil, 1994). A busca pelo contato com a natureza, uma das principais características da demanda turística contemporânea (Giatti, 2004), o desenvolvimento do turismo de base local, muitas vezes associado a unidades de conservação (Ferreira, 2014), e 
a oferta crescente de diferentes tipos de experiências proporcionadas pelo turismo ao ar livre (Passold \& Kinker, 2010) são fatores que apontam para o incremento deste segmento turístico no país. Entretanto, não é possível afirmar, com segurança, que o crescimento da visitação em UCs realmente represente um maior fluxo turístico para essas áreas. Assim, no presente trabalho consideraremos a visitação em UCs em seu aspecto mais geral, podendo representar tanto o fluxo ecoturístico quanto atividades de recreação e lazer ao ar livre ou, ainda, atividades de educação e interpretação ambiental.

Apesar disto, é pertinente considerar que a base conceitual e vários ordenamentos das UCs relacionados à visitação pública tiveram o ecoturismo como referência, como veremos a seguir.

O marco conceitual da visitação em UCs, segundo Passold e Kinker (2010), foi estabelecido em 1997, por meio da publicação Marco Conceitual das Unidades de Conservação Federais do Brasil, que definiu os tipos de atividades que podem ser desenvolvidas pelo público em geral ou por segmentos especializados da sociedade em cada categoria de manejo das UCs. Segundo as autoras, este documento faz referência à desejada participação das comunidades locais nas atividades ecoturísticas, de modo que estas possam contribuir para a melhoria da qualidade de vida e para o desenvolvimento das potencialidades locais. Para tal, sugere a contratação de pessoal local, licitações com empresas locais ou regionais e o desenvolvimento de atividades de interpretação da natureza junto aos visitantes.
O enfoque conceitual da visitação em UCs relacionado ao ecoturismo seguiu, nessa época, as tendências mundiais de um maior interesse pela integridade do meio ambiente, em contraposição aos impactos negativos causados pelo turismo de massa em ambientes naturais. Países como Costa Rica, Equador e Peru, os quais apresentam grande área territorial protegida sob a forma de UCs, foram e continuam sendo importantes referências relacionadas ao desenvolvimento do ecoturismo (Koens, Dieperink \& Miranda, 2009; Hill \& Hill, 2011; Martha, 2012).

Apesar de diversos estados e municípios brasileiros terem, ao longo das décadas de 1980 e 1990, implementado políticas e legislações afeitas ao desenvolvimento da visitação em UCs (Passold e Kinker, 2010), foi com o advento do SNUC (Lei n. 9.985, 2000) que se estabeleceu como um dos objetivos do sistema a promoção da educação e da interpretação ambiental, da recreação em contato com a natureza e do turismo ecológico.

Assim, em face da necessidade de produzir diretrizes e normas para o planejamento e gestão da crescente visitação nas UCs, há pouco mais de uma década o Ministério do Meio Ambiente realizou um diagnóstico da visitação em parques nacionais e estaduais (MMA, 2005). No ano seguinte, com base nos resultados desse estudo, e visando ordenar a visitação nas UCs, através da adoção de regras e medidas que assegurassem a sustentabilidade do turismo, o órgão propôs o documento intitulado Diretrizes para Visitação em Unidades de Conservação (MMA, 2006). Nele, apresentou uma série de princípios, recomendações e diretrizes que visa- 
ram, entre outras, integrar a visitação ao desenvolvimento local e regional, envolver as comunidades locais e populações tradicionais na gestão da visitação e ordenar a prestação dos serviços de apoio à visitação, entre eles aqueles relacionados à condução de visitantes.

No tocante à condução de visitantes nas UCs federais, esta foi primeiramente regulamentada pela Instrução Normativa ICMBio n.08 (2008) do Instituto Chico Mendes de Conservação da Biodiversidade (ICMBio), que estabeleceu "normas e procedimentos para a prestação de serviços vinculados à visitação e ao turismo em Unidades de Conservação Federais por condutores de visitantes". Recentemente, esta norma foi revogada pela Instrução Normativa ICMBio n.02 (2016), que dispôs sobre normas e procedimentos administrativos para autorização de uso para a prestação do serviço de condução de visitantes em unidades de conservação federais. Segundo este regulamento, condutor de visitantes é:

a pessoa física autorizada pelo Instituto Chico Mendes a atuar na condução de visitantes na unidade de conservação, desenvolvendo atividades informativas e interpretativas sobre o ambiente natural e cultural visitado, além de contribuir para o monitoramento dos impactos sócio-ambientais nos sítios de visitação (Instrução Normativa ICMBio n.2, 2016).

A Instrução Normativa ICMBio n.02 (2016) estabeleceu, ainda, que somente poderão atuar como condutores de visitantes as pessoas autorizadas pela administração da UC, nos termos de portaria específica. Além disso, registrou que é desejável que os condutores de visitantes sejam moradores do interior ou do entorno das unidades, de acordo com cada categoria de manejo.

Em relação à regulamentação da atividade de condução de visitantes nas UCs estaduais, Nascimento, Canto-Silva, Melo e Marques (2016) registraram que apenas cinco unidades federativas brasileiras apresentam norma específica para tal, sendo quatro localizadas na região sudeste e uma na região sul. Embora não tenha sido objeto do estudo, os autores também registram a ocorrência de regulamentações sobre o tema em municípios do estado de Santa Catarina.

Assim como a normativa federal, as normativas estaduais citadas reconhecem como condutor de visitantes o prestador desse serviço que, entre outras exigências, apresenta uma qualificação mínima estabelecida pela norma ou pelas UCs (Instrução Normativa ICMBio n.2, 2016; Nascimento et al., 2016), não fazendo referência, portanto, a esta atividade ser prerrogativa de um profissional específico. A normativa federal registra, entretanto, que profissionais com formação em guia de turismo e cadastro vigente no Ministério do Turismo (CADASTUR) poderão receber anterioridade no processo de cadastramento na UC (Instrução Normativa ICMBio n.2., 2016).

De acordo com Canto-Silva, Cunha, Bazotti e Nascimento (2015), dentre as possibilidades de atuação para condução ligadas a ambientes naturais e institucionalmente formalizadas, existem três profissionais: o guia de turismo especializado em atrativo natural, 
o condutor de turismo de aventura e o condutor ambiental local. Os profissionais condutores são denominados genericamente de condutores locais.

Dentre estes, a atuação do guia de turismo foi a primeira a ser reconhecida, através da Lei n. 8.623 (1993). De fato, esta é a única profissão legalmente reconhecida no Brasil para fins de acompanhamento, orientação e transmissão de informações às pessoas ou grupos, em visitas, excursões urbanas, municipais, estaduais, interestaduais, internacionais ou especializadas. O guia de turismo especializado em atrativo natural é reconhecido por portaria recente do Ministério do Turismo (MTUR), que assim denomina o guia cujas atividades compreenderem a prestação de informações técnico-especializadas sobre determinado tipo de atrativo natural (Portaria MTUR n. 27, 2014).

O condutor de turismo de aventura é reconhecido pela atribuição de responsabilidades estabelecidas em normas técnicas da Associação Brasileira de Normas Técnicas (ABNT), através de parceria firmada com o Ministério do Turismo (ABETA, 2009).

Por sua vez, a formalização da atividade do condutor de visitantes em UCs, também nominado condutor ambiental local, se deu pela criação da Instrução Normativa ICMBio n.08 (2008), sendo reconhecida de maneira mais formal através da Portaria MTUR n. 27 (2014), que define o condutor de visitantes em UC como:

o profissional que recebe capacitação específica para atuar em determinada unidade, cadastrado no órgão gestor, e com a atribuição de conduzir visitantes em espaços naturais e/ou áreas legalmente protegidas, apresentando conhecimentos ecológicos vivenciais, específicos da localidade em que atua, estando permitido conduzir apenas nos limites desta área (Portaria MTUR n. 27, 2014).

O condutor ambiental local é preferencialmente um integrante da região onde está localizada a UC, de modo que é capaz de passar seus conhecimentos de vivência do meio biológico e cultural local, tornando-se assim também parte do atrativo, já que promove um intercâmbio cultural (Ribas e Hickenbick, 2012).

Embora a atividade de condução de visitantes seja fundamental para o uso público em UCs, pouco se conhece em relação à forma como vem sendo realizada, se atende ou não as normas vigentes e quais profissionais de fato vêm atuando.

\section{PROCEDIMENTOS METODOLÓGICOS}

A metodologia do presente estudo consistiu em pesquisa documental junto ao Cadastro Nacional de Unidades de Conservação (CNUC) e no levantamento de informações entre os gestores dos Parques brasileiros. Para o escopo deste trabalho foram consideradas as três esferas de gestão, contemplando os Parques Nacionais, Estaduais e Naturais Municipais.

A pesquisa no CNUC foi realizada em novembro de 2015, sendo, portanto, considerada a realidade observada naquele momento. A partir das informações pesquisadas, foi constituído um banco de dados constando: nome do Parque, esfera de gestão (fe- 
deral, estadual ou municipal), bioma localizado (Amazônia, Caatinga, Cerrado, Marinho, Mata Atlântica, Pampa ou Pantanal), existência de Plano de Manejo (sim ou não), situação da visitação (aberto à visitação, fechado à visitação ou sem informação) e endereço eletrônico do gestor.

O levantamento de informações entre os gestores das UCs foi feito por meio de questionário elaborado e enviado eletronicamente a estes através da ferramenta Google.docs. O questionário foi constituído por 7 questões fechadas ou abertas, abordando: identificação do Parque; ocorrência de visitação (sim ou não); número anual de visitantes (menos de 1.000 , de 1.000 a 5.000 , de 5.000 a 10.000, acima de 10.000); responsável pela condução de visitantes (sem condução, condutores locais ou guias especializados em atrativos naturais); cadastramento dos condutores de visitantes no Parque (sim ou não); atuação dos condutores de visitantes (autônoma ou associativada); e identificação das associações, cooperativas ou coletivos de condutores de visitantes que atuam na U.C.
Os questionários foram enviados aos gestores de todos os Parques por pelo menos oito vezes, nos meses de dezembro de 2015 e julho de 2016. Para a pesquisa junto aos Parques Nacionais foi obtida Autorização para Atividades com Finalidade Científica.

Dos 368 questionários enviados aos gestores dos Parques, obteve-se o retorno de 74 questionários respondidos, equivalente a $20,11 \%$ do total (Tabela 1). Considerando-se as esferas de gestão, foram amostrados 47,89\% dos Parques Nacionais, $13,27 \%$ dos Parques Estaduais e 13,86\% dos Parques $\mathrm{Na-}$ turais Municipais. Entretanto, quando considerado apenas o número de Parques com visitação amostrados (64) em relação ao quantitativo deles no CNUC (123), este percentual alcança 93,75\% dos Parques Nacionais, $47,83 \%$ dos Estaduais e $12,67 \%$ dos Parques administrados pela esfera municipal. Esta composição amostral indica que os dados utilizados são muito representativos da realidade que se pretende caracterizar.

Tabela 1 - Quantidade e percentual dos Parques amostrados em relação ao total de Parques cadastrados e total de Parques com visitação, conforme dados do CNUC

\begin{tabular}{ccccc}
\hline $\begin{array}{c}\text { Esfera de ges- } \\
\text { tão }\end{array}$ & $\begin{array}{c}\text { Parques cadas- } \\
\text { trados }\end{array}$ & $\begin{array}{c}\text { Parques amos- } \\
\text { trados (\%) }\end{array}$ & $\begin{array}{c}\text { Parques com } \\
\text { visitação }\end{array}$ & $\begin{array}{c}\text { Parques amos- } \\
\text { trados (\%) }\end{array}$ \\
\hline Federal & 71 & $34(47,89)$ & 32 & $30(93,75)$ \\
Estadual & 196 & $26(13,27)$ & 46 & $22(47,83)$ \\
Municipal & 101 & $14(13,86)$ & 45 & $12(26,67)$ \\
Total & 368 & $74(20,11)$ & 123 & $64(52,03)$ \\
\hline
\end{tabular}

Fonte: Autoria própria

Fizeram parte desta pesquisa os seguintes Parques Nacionais: Parna Campos Gerais, Parna da Boa Nova, Parna da Chapada das Mesas, Parna da Chapada Diamantina, Parna da Chapada dos Guimarães, Parna da Ilha Grande, Parna da Lagoa do Peixe, Parna 
da Serra da Bocaina, Parna da Serra da Canastra, Parna da Serra do Divisor, Parna da Serra do Itajaí, Parna da Serra dos Órgãos, Parna da Serra Geral, Parna da Tijuca, Parna das Emas, Parna das Sempre-Vivas, Parna de Anavilhanas, Parna de Catimbau, Parna de Saint-Hilaire/Lange, Parna de São Joaquim, Parna do Jaú, Parna do Juruena, Parna do Superagui, Parna do Viruá, Parna Grande Sertão Veredas, Parna Itatiaia, Parna Marinho dos AbroIhos, Parna Marinho Fernando de Noronha, Parna Nascentes do Rio Parnaíba e Parna Serra da Capivara.

Na esfera estadual, participaram: PE Alto Cariri, PE Cachoeira da Fumaça, PE Chandless, PE da Costa do Sol, PE da Pedra Azul, PE da Serra da Concórdia, PE da Serra do Rola Moça, PE da Serra Selada, PE das Sete passagens, PE de Grão Mogol, PE de Vila Velha, PE do Biribiri, PE do Juquery, PE do Morro do Diabo, PE do Pico do Itambé, PE do Prosa, PE do Rio Doce, PE do Utinga, PE Fritz Plaumann, PE Serra do Mar - Núcleo São Sebastião, PE Serra Negra e PE Sitio Fundão.

$\mathrm{Na}$ esfera municipal foram obtidas informações dos seguintes parques: PNM Felisberto Neves, PNM da Mata Atlântica Aldeense, PNM de Navegantes, PNM Corredores de Biodiversidade, PNM de Governador Valadares, PNM do Atalaia, PNM Von Schilgen, PNM do Curió - Paracambi, PNM do Morro do Finder, PNM da Caieira, PNM Nascentes de Paranapiacaba e Parque Histórico Municipal Danziger Hoff.
Todos os resultados obtidos na pesquisa foram apresentados sob a forma de percentagem, sendo analisados, portanto, apenas em nível descritivo (Silva, Gonçalves \& Murolo, 1997). Os dados relativos à visitação dos parques foram avaliados cruzando-se informações obtidas para as esferas de gestão, existência de plano de manejo na unidade e o bioma de localização da mesma. As respostas dos entrevistados foram analisadas por esfera de gestão dos Parques. Os resultados foram comparados com os da literatura pertinente, em especial MMA (2005) e MMA (2006).

\section{RESULTADOS}

O banco de dados elaborado a partir do CNUC reuniu 368 unidades de conservação da categoria Parque, incluindo Nacionais, Estaduais e Naturais Municipais de todo o Brasil. De acordo com as informações obtidas, é possível traçar os seguintes cenários quanto à realidade dessas áreas protegidas.

A esfera estadual contém o maior número de Parques registrados no CNUC. Somam 196, o que corresponde a 53,3\% do total de Parques (Figura 1A). Os Parques Naturais Municipais totalizam 101 (27,4\%) e os Parques Nacionais 71 (19,3\%) (Figura 1A). O bioma Mata Atlântica é aquele que está mais bem representado entre os Parques, correspondendo a 59,8\% destes (Figura 1B). 
Figura 1 - Frequência de Parques cadastrados no CNUC: entre as diferentes esferas de gestão (A); entre os diferentes biomas brasileiros (B)
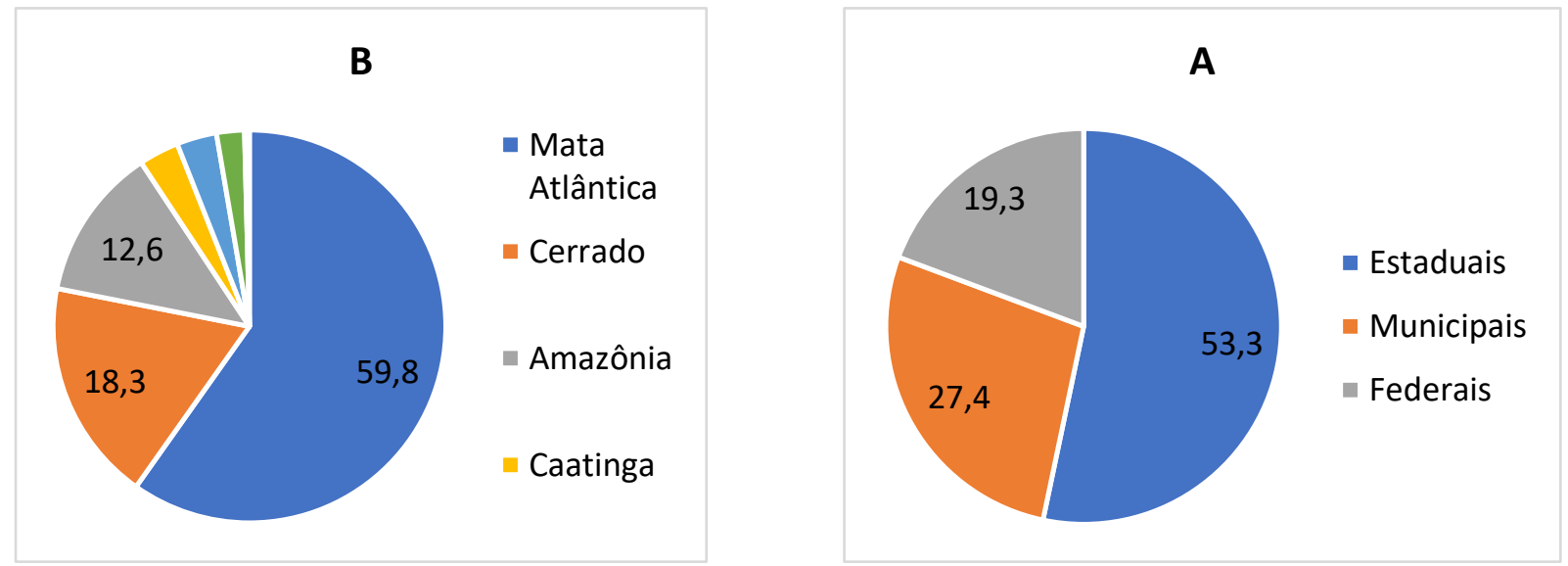

Fonte: Autoria própria

Com relação à existência do Plano de Manejo, a maioria dos parques, em qualquer esfera considerada, não apresenta este documento (Figura 2). A esfera de gestão cujo percentual de Parques com Planos de Manejo é maior é a Federal, alcançando 47,89\%
(Figura 2). Os Parques Naturais Municipais, administrados pela esfera municipal, são aqueles que apresentam o menor percentual de unidades atendendo a legislação $(19,80 \%)$.

Figura 2 - Frequência de Parques com e sem Plano de Manejo em cada esfera de gestão, conforme dados do CNUC

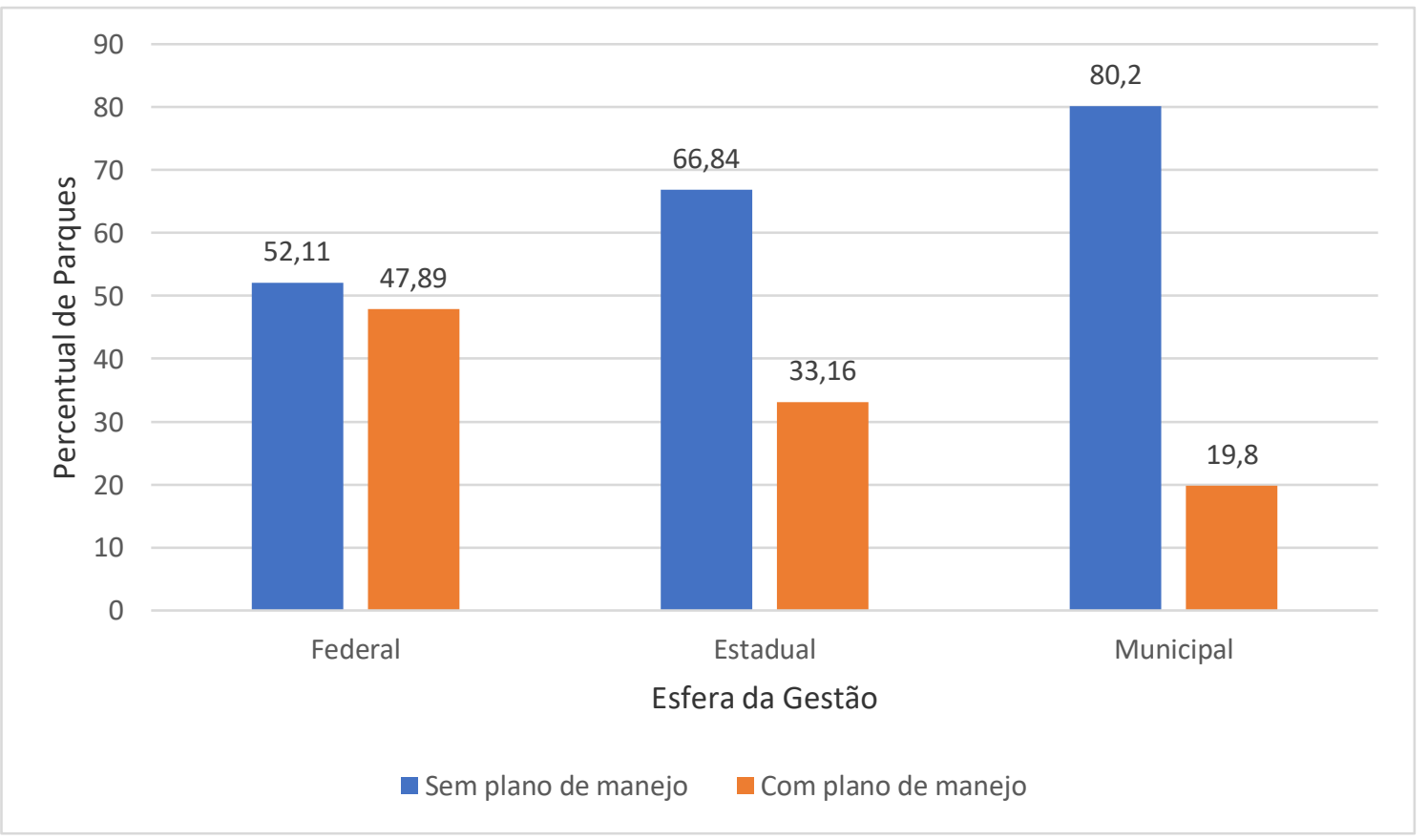

Fonte: Autoria própria 
Referente à visitação nos Parques brasileiros, evidencia-se o fato que $55,4 \%$ daqueles cadastrados no CNUC não disponibilizam tal informação (Figura 3A). Assim, considerando o total de parques, pode-se afirmar que apenas $33,42 \%$ estão abertos à visitação (Figura 3A). Outra questão digna de registro é que, a despeito da legislação estabelecer que apenas UCs com Plano de Manejo estão aptas a desenvolver atividades de uso público, 25,7\% dos Parques sem Plano de Manejo estão abertos à visitação (Figura 3C). Quando considerados apenas os Parques com Plano de Manejo, o percentual com visitação alcança 49,6\% (Figura 3B).

Considerando a atividade de visitação por esfera de gestão (Tabela 2), os Parques
Estaduais são aqueles que apresentam o maior número de unidades sem essa informação no CNUC (63,35\%). São aqueles também que apresentam o menor percentual de unidades com visitação $(23,47 \%)$, seja entre aquelas com Plano de Manejo $(36,92 \%)$ ou sem Plano de Manejo $(16,79 \%)$. Os Parques Nacionais e Naturais Municipais são aqueles que apresentam o maior percentual de unidades com visitação, respectivamente $45,07 \%$ e $44,55 \%$.

Constata-se também, com base na Tabela 2, que os Parques Naturais Municipais são aqueles em que a ocorrência de visitação sem Plano de Manejo é mais frequente. Em $38,27 \%$ das unidades que não possuem esse documento ocorre a visitação.

Figura 3 - Frequência de Parques cadastrados no CNUC com relação à visitação: Total de Parques (A); Parques com Plano de Manejo (B); Parques sem Plano de Manejo (C).

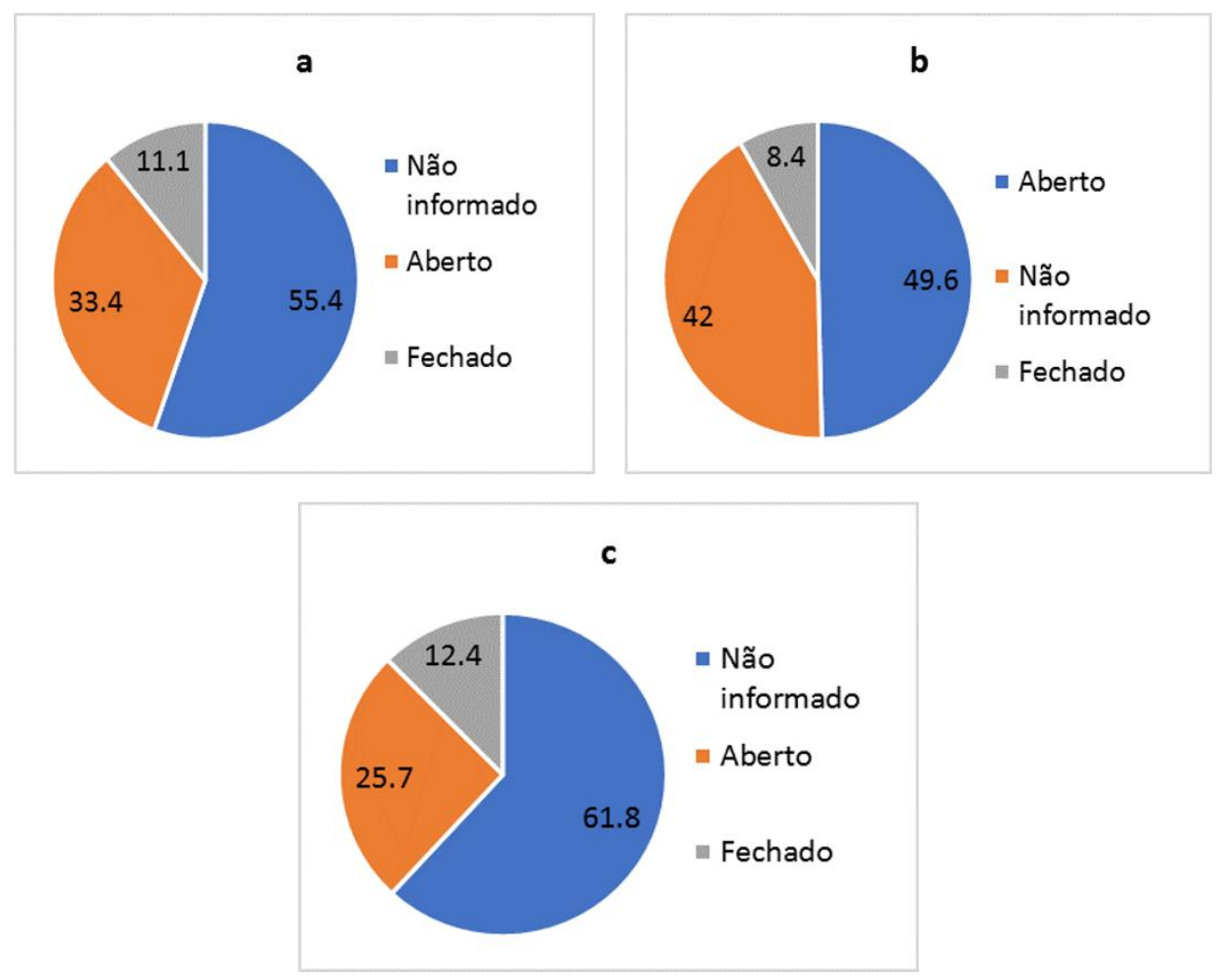

Fonte: Autoria própria 
Tabela 2 - Quantidade e percentual de Parques abertos ou fechados à visitação por esfera de gestão e por existência de Plano de Manejo, conforme dados do CNUC

\begin{tabular}{|c|c|c|c|c|c|}
\hline $\begin{array}{c}\text { Esfera de gestão do } \\
\text { Parque }\end{array}$ & $\begin{array}{c}\text { Existência } \\
\text { de Plano de } \\
\text { Manejo }\end{array}$ & $\begin{array}{l}\text { Abertos à vi- } \\
\text { sitação (\%) }\end{array}$ & $\begin{array}{l}\text { Fechados à } \\
\text { visitação (\%) }\end{array}$ & $\begin{array}{l}\text { Sem informa- } \\
\text { ção (\%) }\end{array}$ & Total \\
\hline & Sim & $21(61,76)$ & $3(8,82)$ & $10(29,41)$ & 34 \\
\hline \multirow[t]{3}{*}{ Federal } & Não & $11(29,73)$ & $9(24,32)$ & $17(49,95)$ & 37 \\
\hline & Total & $32(45,07)$ & $12(16,90)$ & $27(38,02)$ & 71 \\
\hline & Sim & $24(36,92)$ & $7(10,77)$ & $34(53,31)$ & 65 \\
\hline \multirow[t]{3}{*}{ Estadual } & Não & $22(16,79)$ & $11(8,40)$ & $98(74,81)$ & 131 \\
\hline & Total & $46(23,47)$ & $18(9,18)$ & $132(63,35)$ & 196 \\
\hline & Sim & $14(70)$ & 0 & $6(30,00)$ & 20 \\
\hline \multirow[t]{2}{*}{ Municipal } & Não & $31(38,27)$ & $11(13,58)$ & $39(48,15)$ & 81 \\
\hline & Total & $45(44,55)$ & $11(10,89)$ & $45(44,55)$ & 101 \\
\hline Total & & $123(33,42)$ & $41(11,14)$ & $204(55,43)$ & 368 \\
\hline
\end{tabular}

Fonte: Autoria própria

Quando analisados os dados contidos no CNUC referentes à visitação nos Parques por bioma (Tabela 3), constata-se que, exceto o bioma Amazônia, nos demais a frequência de Parques sem essa informação é superior a $50 \%$. Os biomas que apresentam a maior frequência de Parques com visitação são a Caatinga (40,00\%) e a Mata Atlântica (38,91\%). Desconsiderando-se o bioma Pantanal, que não apresenta Parques abertos à visitação, o bioma Amazônia é aquele que apresenta a menor frequência de Parques com essa atividade $(26,09 \%)$, valor equivalente ao percentual de Parques que não apresentam a mesma. Exceto o bioma Pampa, todos os demais apresentam Parques sem Plano de Manejo abertos à visitação. Cabe ressaltar, entretanto, que as frequências apresentadas devem ser avaliadas com cautela em face das diferentes quantidades de UCs dessa categoria por bioma.

Com base nas informações dos gestores das UCs, obtidas através dos questionários retornados, é possível afirmar que, em relação à estimativa de visitantes, mais de $50 \%$ dos Parques Nacionais e Estaduais atendem um público anual superior a 10.000 visitantes (Tabela 4). Os parques naturais municipais apresentam uma distribuição relativamente uniforme entre as categorias de quantidade de visitantes avaliadas, preponderando aqueles que atendem menos de 1.000 visitantes por ano. Considerando o total de parques, $46,88 \%$ deles atendem um público anual acima de 10.000 visitantes.

Referente aos prestadores de serviço de condução de visitantes, considerando-se o total dos parques, mais da metade $(52,13 \%)$ é atendida exclusivamente por condutores locais (Tabela 4). No entanto, é possível afirmar que esses profissionais estão envolvidos na condução de visitantes em $81,25 \%$ dos Parques avaliados. Por outro lado, em apenas $6,25 \%$ destes o atendimento é feito exclusivamente por guias especializados em atrativos naturais, estando estes, por sua vez, envolvidos num total de $18,75 \%$ dos Parques. Este mesmo panorama é observado quando considerados isoladamente os parques das diferentes esferas de gestão (Tabela 4).

A Tabela 4 revela, em relação ao cadastramento dos condutores de visitantes 
nos parques, que a frequência de unidades em que ocorre o cadastramento dos prestadores de serviço $(54,69 \%)$ é pouco superior àquelas em que não ocorre 0 cadastramento (45,31\%). O mesmo padrão é observado quando considerados os parques em cada esfera de gestão, exceto para os Parques Estaduais, onde há um equilíbrio entre 0 cadastramento e $o$ não cadastramento dos condutores de visitantes.

No que diz respeito à atuação dos condutores de visitantes, em 60,94\% dos Parques estes atuam de forma autônoma, enquanto em $39,06 \%$ a atuação se dá de forma associativada, por meio de associações, cooperativas ou outros coletivos (Tabela 4). Considerando-se as diferentes esferas de gestão, apenas em Parques Nacionais a proporção entre as duas formas de atuação é mais equilibrada, com 53,33\% e $46,67 \%$, respectivamente para atuação autônoma e associativada (Tabela 4). Coerentemente, são os Parnas os responsáveis por 22 dos 32 registros de entidades associativas citadas no trabalho. Os Parques Nacionais da Chapada Diamantina, da Serra da Capivara e dos Aparados da Serra/Serra Geral foram os que contribuíram com o maior número de registros.

Tabela 3 - Quantidade e percentual de Parques abertos ou fechados à visitação por Bioma e por existência de Plano de Manejo, conforme dados do CNUC.

\begin{tabular}{|c|c|c|c|c|c|}
\hline Bioma & $\begin{array}{c}\text { Existência } \\
\text { de Plano de } \\
\text { Manejo }\end{array}$ & $\begin{array}{l}\text { Abertos à visi- } \\
\text { tação (\%) }\end{array}$ & $\begin{array}{l}\text { Fechados à vi- } \\
\text { sitação (\%) }\end{array}$ & $\begin{array}{c}\text { Sem } \\
\text { Informação (\%) }\end{array}$ & Total \\
\hline & Sim & $8(40,00)$ & $4(20,00)$ & $8(40,00)$ & 20 \\
\hline \multirow[t]{3}{*}{ Amazônia } & Não & $4(15,38)$ & $8(30,77)$ & $14(53,85)$ & 26 \\
\hline & total & $12(26,09)$ & $12(26,09)$ & $22(47,83)$ & 46 \\
\hline & Sim & $3(75,00)$ & 0 & $1(25,00)$ & 4 \\
\hline \multirow[t]{3}{*}{ Caatinga } & Não & $3(27,27)$ & 0 & $8(72,73)$ & 11 \\
\hline & total & $6(40,00)$ & 0 & $9(60,00)$ & 15 \\
\hline & Sim & $9(39,13)$ & $3(13,04)$ & $11(47,83)$ & 23 \\
\hline \multirow[t]{3}{*}{ Cerrado } & Não & $5(11,36)$ & $6(13,64)$ & $33(75,00)$ & 44 \\
\hline & total & $14(26,90)$ & $9(13,43)$ & $44(65,67)$ & 67 \\
\hline & Sim & $1(33,33)$ & 0 & $2(66,67)$ & 3 \\
\hline \multirow[t]{3}{*}{ Marinho } & Não & $3(30,00)$ & 0 & $7(70,00)$ & 10 \\
\hline & total & $4(30,77)$ & 0 & $9(69,23)$ & 13 \\
\hline & Sim & $37(55,22)$ & $2(2,99)$ & $28(41,79)$ & 67 \\
\hline \multirow[t]{3}{*}{ Mata Atlântica } & Não & $49(31,82)$ & $17(11,04)$ & $88(57,14)$ & 154 \\
\hline & total & $86(38,91)$ & $19(8,60)$ & $116(52,49)$ & 221 \\
\hline & Sim & $1(100)$ & 0 & 0 & 1 \\
\hline \multirow[t]{3}{*}{ Pampa } & Não & 0 & 0 & $2(100)$ & 2 \\
\hline & total & $1(33,33)$ & 0 & $2(66,67)$ & 3 \\
\hline & Sim & 0 & $1(100)$ & 0 & 1 \\
\hline \multirow[t]{2}{*}{ Pantanal } & Não & 0 & 0 & $2(100)$ & 2 \\
\hline & total & 0 & $1(33,33)$ & $2(66,67)$ & 3 \\
\hline Total & & $123(33,42)$ & $41(11,14)$ & $204(55,43)$ & 368 \\
\hline
\end{tabular}

Fonte: Autoria própria 
Tabela 4 - Quantidade e percentual de Parques com visitação, por esfera de gestão, em relação a estimativa de visitantes, aos prestadores do serviço de condução de visitantes e a atuação dos condutores de visitantes.

\begin{tabular}{|c|c|c|c|c|c|}
\hline \multirow{2}{*}{ Item } & \multirow{2}{*}{ Opções } & \multicolumn{3}{|c|}{ Esfera de gestão do Parque } & \multirow{2}{*}{ Total (\%) } \\
\hline & & Federal (\%) & Estadual (\%) & Municipal (\%) & \\
\hline \multirow{5}{*}{ 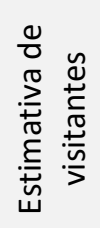 } & Menos de 1.000 & $7(23,33)$ & $4(18,88)$ & $4(33,33)$ & $15(23,44)$ \\
\hline & De 1.000 a 5.000 & $6(20,00)$ & $4(18,88)$ & $3(25,00)$ & $13(20,31)$ \\
\hline & De 5.000 a 10.000 & $1(3,33)$ & $3(13,64)$ & $2(16,67)$ & $6(9,38)$ \\
\hline & Acima de 10.000 & $16(53,33)$ & $11(50,00)$ & $3(25,00)$ & $30(46,88)$ \\
\hline & Total & 30 & 22 & 12 & 64 \\
\hline \multirow{14}{*}{ 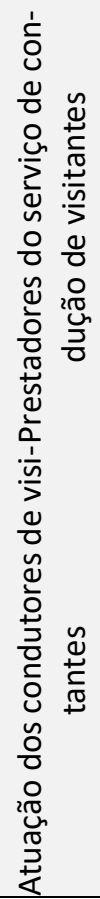 } & Apenas condutores locais & $13(43,33)$ & $13(59,09)$ & $8(66,67)$ & $34(52,13)$ \\
\hline & $\begin{array}{l}\text { Apenas guias especializados em atrativos natu- } \\
\text { rais }\end{array}$ & 0 & $2(9,09)$ & $2(16,67)$ & $4(6,25)$ \\
\hline & $\begin{array}{l}\text { Condutores locais e guias especializados em } \\
\text { atrativos naturais }\end{array}$ & $3(10,00)$ & $2(9,09)$ & 0 & $5(7,81)$ \\
\hline & Sem condução & $4(13,33)$ & $2(9,09)$ & $2(16,67)$ & $8(12,50)$ \\
\hline & Sem condução e condutores locais & $8(26,67)$ & $2(9,09)$ & 0 & $10(15,63)$ \\
\hline & $\begin{array}{l}\text { Sem condução, condutores locais e guias espe- } \\
\text { cializados em atrativos naturais }\end{array}$ & $2(6,67)$ & $1(4,55)$ & 0 & $3(4,69)$ \\
\hline & Total & 30 & 22 & 12 & 64 \\
\hline & $\begin{array}{l}\text { Condutores de visitantes cadastrados no Par- } \\
\text { que }\end{array}$ & $17(56,67)$ & $11(50,00)$ & $7(58,33)$ & $35(54,69)$ \\
\hline & $\begin{array}{l}\text { Condutores de visitantes não cadastrados no } \\
\text { Parque }\end{array}$ & $13(43,33)$ & $11(50,00)$ & $5(41,67)$ & $29(45,31)$ \\
\hline & Total & 30 & 22 & 12 & 64 \\
\hline & Condutores de visitantes autônomos & $16(53,33)$ & $14(63,64)$ & $9(75,00)$ & $39(60,94)$ \\
\hline & Condutores de visitantes associativados & $14(46,67)$ & $8(36,36)$ & $3(25,00)$ & $25(39,06)$ \\
\hline & Total & 30 & 22 & 12 & 64 \\
\hline & $\begin{array}{l}\text { Número de associações, cooperativas e demais } \\
\text { coletivos de condutores de visitantes }\end{array}$ & 22 & 7 & 3 & 32 \\
\hline
\end{tabular}

Fonte: Autoria própria 


\section{DISCUSSÃO}

Sem dúvida, a implementação do Plano de Manejo nos Parques é fundamental para, entre outras questões, permitir o planejamento e a ordenação do uso público nessas áreas. Entretanto, passados 16 anos da Lei do SNUC, que estabeleceu a obrigatoriedade da elaboração desse documento técnico para todas as categorias de UCs, a realidade constatada é ainda distante do estabelecido pela legislação.

Apesar desse panorama, esta realidade tem evoluído na última década. Segundo estudo do ICMBio (2011), referente à avaliação comparada da efetividade da gestão em UCs federais, nos ciclos 2005-06 e 2010, ao longo desse período o percentual de Parques Nacionais com Plano de Manejo passou de $30,9 \%$ para $50 \%$. Infelizmente, nos últimos anos parece não ter havido muita mudança desse patamar, uma vez que o percentual observado no presente trabalho, para Parques Nacionais, não é muito diferente (47,89\%). Medeiros e Pereira (2011), em estudo sobre a evolução e implementação dos planos de manejo em Parques Nacionais no estado do Rio de Janeiro, também constataram que, em geral, os Planos de Manejo não foram elaborados, nem revisados dentro dos prazos e periodicidade estabelecidos pela legislação. Para os autores, isso denota uma dificuldade na implementação desse instrumento de gestão, provavelmente em face da grande complexidade envolvida na sua confecção e, consequentemente, da grande demanda de tempo e recursos financeiros, geralmente reduzidos nos orçamentos das UCs.
Provavelmente, tal contexto seja aplicado às demais esferas de gestão - estadual e municipal -, o que pode explicar a inexistência de Planos de Manejo em muitos Parques Estaduais e Parques Naturais Municipais.

Deve-se ressaltar a ausência de informações sobre a visitação em mais da metade dos Parques cadastrados no CNUC. Provavelmente isso se deva ao fato que muitas dessas UCS estão ainda apenas no papel, não podendo ser consideradas áreas protegidas realmente implementadas.

Comparando-se os dados de visitação obtidos neste trabalho para Parques Nacionais e Estaduais com aqueles registrados no diagnóstico da visitação nessas UCs realizado em 2005 (MMA, 2005), constata-se que o panorama não se alterou muito, uma vez que aquele trabalho apontou que a visitação ocorria em 23 de 52 Parques Nacionais (44,23\%) e em 41 de 155 Parques Estaduais (26,45\%), valores percentuais muito próximos aos obtidos no presente estudo.

O baixo percentual de Parques Estaduais que apresentam visitação $(23,47 \%)$ pode refletir as dificuldades de planejamento vivenciadas por essa esfera administrativa na gestão das áreas protegidas. Isto fica evidente pelo reduzido número de Parques Estaduais com Plano de Manejo e com informações sobre a ocorrência ou não de visitação. Contrastando, o percentual de Parques Naturais Municipais com visitação é muito semelhante ao dos Parques Nacionais, apesar de apenas uma pequena parcela apresentar Plano de Manejo e informações sobre a visitação. Possivelmente, a maior 
quantidade de unidades com visitação resulte da localização dessas em áreas urbanas, com grande pressão pela visitação.

$O$ fato de muitos Parques sem Plano de Manejo apresentarem visitação não chega a ser uma irregularidade em todas as situações. É possível que uma parcela destes possua Plano Emergencial de Uso Público, regulamento provisório que estabelece normas para a visitação no Parque até a publicação do seu Plano de Manejo (IEF, 2015) ou Portaria de Ordenamento da Visitação, documento que oferece aos gestores ferramentas para a gestão do uso público e estabelecem, dentre as atividades existentes, quais serão permitidas e em quais áreas da UC (Castro \& Kinker,2012).

No presente trabalho foi registrado que 53,33\% dos Parques Nacionais atendem um público anual superior a 10.000 visitantes. Esta realidade é um pouco diferente daquela observada em 2005, quando o diagnóstico da visitação em Parques Nacionais apontou que aproximadamente $79 \%$ deles atendiam um público anual superior a 10.000 visitantes (MMA, 2005). Entretanto, cabe ressaltar que Parques Nacionais importantes em termos de visitação como o Parna do Iguaçu, Parna de Jericoacoara e Parna de Brasília não participaram da presente pesquisa.

No que diz respeito à prestação do serviço de condução de visitantes nos Parques brasileiros, a altíssima contribuição dos condutores locais confirma uma tendência já constatada no diagnóstico da visitação em Parques Nacionais e Estaduais realizado em 2005 (MMA, 2005). Nesse trabalho, estes profissionais denominados "guias locais" já eram os principais prestadores do serviço de condução de visitantes nos Parques de todas as regiões brasileiras, exceto na Região Norte, onde predominavam os "guias de empresas" (MMA, 2005).

Esse fortalecimento do papel dos condutores locais nas UCs é mencionado por Ribas e Hickenbick (2012) em trabalho sobre o papel dos condutores ambientais locais e dos cursos de capacitação no ecodesenvolvimento turístico do Sul do Brasil. As autoras pontuam que a publicação da Instrução Normativa ICMBio n.08 (2008), que regulamentou a atividade dos condutores de visitantes nas UCs federais, foi fundamental para que houvesse um grande interesse dos órgãos públicos estaduais e municipais em também regulamentarem a atuação de condutores localmente. Isso, segunda as autoras, tem promovido o reconhecimento do condutor com um profissional do eixo do turismo e levado os Ministérios do Turismo (MTur), do Meio Ambiente (MMA) e da Educação (MEC) se articularem na tentativa de regulamentar a atuação e capacitação desse profissional.

A prevalência dos condutores locais na prestação dos serviços de condução de visitantes em Parques é muito pertinente para o desenvolvimento de um turismo ecológico, uma vez que isso contribui para a satisfação das necessidades socioeconômicas das regiões receptoras. Canto-Silva et al. (2015) chamam a atenção justamente para o fato que a atuação de condutores ambientais locais em UCs contribuem para a quebra de paradigmas excludentes, ao adotar a estratégia de agregar os saberes e fazeres dos moradores das áreas de entorno dessas áreas protegidas, gerando, além disso, oportunidades de trabalho e renda para eles.

Os resultados referentes ao cadastra- 
mento dos condutores de visitantes nos Parques evidenciam que uma das diretrizes estabelecida no documento "Diretrizes para Visitação em Unidades de Conservação" (MMA, 2006), que requer que todos os condutores, monitores e guias estejam devidamente cadastrados nas UC onde atuam, ainda está longe de ser alcançada. Certamente tal realidade está associada ao fato, pontuado por Nascimento et al. (2016), que apenas $18,5 \%$ das unidades federativas do Brasil possuem base legal que estabeleça normas e procedimentos para a prestação de serviços de condução de visitantes em suas UCs. Os dados obtidos neste trabalho corroboram tal afirmativa, uma vez que a esfera estadual foi justamente aquela que apresentou o maior percentual de Parques cujos condutores de visitantes não estão cadastrados na unidade.

Por fim, os dados obtidos permitem registrar que embora o condutor de visitantes ainda seja em sua maioria um profissional autônomo, é muito significante a parcela dos Parques em que atuam condutores de forma associativada. Isto também pode ser visto como um fator pertinente ao turismo ecológico, uma vez que, segundo o Ministério do Trabalho (MTE, 2011), a economia solidária é uma forma de produção, comercialização e consumo que promove a autogestão dos processos de trabalho, considerando critérios de eficácia ao lado de aspectos sociais e ambientais.

\section{CONCLUSÃO}

A ausência de Planos de Manejo e, até mesmo, da implementação efetiva dos
Parques ainda é uma realidade a ser superada. Isto certamente impacta de forma negativa a ocorrência da visitação na maioria dos Parques brasileiros. Mais do que a ausência do Plano de Manejo, outros fatores parecem ser mais determinantes para esta realidade, talvez aqueles relacionados à carência de infraestrutura física e capacidade de gestão dessas áreas protegidas.

Os percentuais de Parques com visitação, pelo menos no que diz respeito aos Nacionais e Estaduais, parecem não ter se alterado nos últimos 10 anos. 0 incremento de visitantes observado nesse mesmo período provavelmente reflete o aumento da visitação nos Parques em que a atividade já está consolidada, principalmente em se tratando de Parques Nacionais. Percebe-se também que os Parques Naturais Municipais contribuem de forma significante com a visitação em Parques, embora não em termos de quantidade de visitantes.

Importante conclusão a ser retirada deste trabalho é o papel protagonista dos condutores locais na condução de visitantes nos Parques brasileiros. Isto fica muito evidente a partir dos dados analisados, corroborando as tendências nesse sentido observadas nos últimos anos e refletindo as iniciativas em prol de um turismo ecológico, baseado na inclusão das comunidades do entorno dessas áreas protegidas. Conclui-se, também, que a relação administrativa dos condutores de visitantes com os Parques ainda não é adequada em todas as unidades estudadas, necessitando a implementação de instrumentos legais que melhor ordenem a atuação desses profissionais. Por outro lado, a organização dos condutores de 
visitantes em associações, cooperativas e outros coletivos é uma realidade, embora ainda não predomine como forma de atuação nos Parques estudados.

Por fim, acreditamos que o presente trabalho contribui com informações atualizadas do panorama da visitação e da condução de visitantes nos Parques brasileiros. Algumas questões surgem a partir do cenário traçado, apontando para a necessidade de um melhor planejamento e gestão da visitação em Parques. Fica evidente a necessidade de um maior financiamento dessas áreas para que estas consigam efetivamente constituir instrumentos de gestão e infraestrutura necessários à visitação. Por outro lado, em face do importante papel da comunidade local na atividade de condução de visitantes nos parques, é pertinente que mais estudos sejam desenvolvidos sobre o perfil, as limitações e as necessidades desses profissionais, de modo a melhorar a qualidade de vida dos envolvidos e qualificar os serviços de visitação oferecidos nas UCs. Finalmente, fica evidente também que o estabelecimento de regulamentações referentes à condução de visitantes nas diferentes esferas de gestão é uma demanda importante para o melhor ordenamento da atividade nessas áreas.

\section{REFERÊNCIAS}

ABETA. (2009). Associação de Empresas de Ecoturismo e Turismo de Aventura; Ministério do Turismo. Manual de boas práticas de rafting. Belo Horizonte: Editora dos autores, 2009. (Série Aventura Segura). Recuperado em 20 setembro, 2016, de <http://www.aventurase-
gura.org.br/wp-content/uploads/2012/08/Brasil_ABETA_Vol_10_-Rafting_Manual_Boas_Praticas.pdf> Acesso em: 23 mai. 2013.

Brasil, Ministério do Meio Ambiente, dos Recursos Hídricos e da Amazônia Legal. Ministério da Indústria e Comércio e Instituto Brasileiro do Turismo. (1994). Diretrizes para uma política naciona: ecoturismo. Brasília: MMA, MICT, Embratur

Canto-Silva, C. R., Cunha, A. M., Bazotti, L. S. \& Nascimento, C. A. (2015). Formação e Organização de Condutores Ambientais Locais: Estratégias de Desenvolvimento do Turismo Sustentável em Unidades de Conservação Gaúchas.. In: VII Seminário Brasileiro sobre Áreas Protegidas e Inclusão Social ? SAPIS e Encontro Latino Americano sobre Áreas Protegidas e Inclusão Social, 2015, Florianópolis. Anais do VII Seminário Brasileiro sobre Áreas Protegidas e Inclusão Social SAPIS e Encontro Latino Americano sobre Áreas Protegidas e Inclusão Social - ELAPIS, 2015. Florianópolis, 2015.

Castro, E. B. V \& Kinker, S. M. S. (2012) Ordenamento da Visitação como estratégia de proteção de unidades de conservação: os casos dos Parques Nacionais de Anavilhanas e São Joaquim. In: Anais do VII CBUC - Congresso Brasileiro de Unidades de Conservação, 2012, Natal, RN.

Cutolo, S. A., Malheiros, T. F. \& Philippi Jr., A. (2010). Potencial Turísitco e Saneamento Ambiental em Unidades de Consevação. In Philippi Jr., A. \& Ruschmann, D. V. M. (Org.). (2010). Gestão Ambiental e Sustentabilidade no Turismo (Coleção Ambiental, v. 9). Barueri, SP: Manole.

Decreto Legislativo n. 5.758, de 13 de abril de 2006 (2006). Institui o Plano Estratégico Nacional de Áreas Protegidas - PNAP, seus princípios, diretrizes, objetivos e estratégias, e dá outras providências. Brasília, DF. Recuperado em 10 juIho, 2016, de https://www.planalto.gov.br/ccivil 03/Ato2004-2006/2006/Decreto/D5758.htm

Drummond, J. A., Franco, J. L. A. \& Oliveira, D. (2010). Uma análise sobre a história e a situação 
das unidades de conservação no Brasil in Ganem, R. S. (Org.). (2010). Conservação da biodiversidade: legislação e políticas públicas (Série memória e análise de leis, n. 2). Brasília: Câmara dos Deputados.

Ferreira, H. C. H. (2014). Turismo comunitário, tradicionalidade e reserva de desenvolvimento sustentável na defesa do território nativo: aventureiro-Ilha Grande/RJ. Revista Brasileira de Pesquisa em Turismo, v. 8 (2), p. 361-379. Recuperado em 29 abril, 2017, de

https://rbtur.org.br/rbtur/article/view/689/647.

Ferreira, L. F. \& Coutinho, M. C. B. (2010). Ecoturismo: a Importância da Capacitação Profissional do Condutor Ambiental Local. In Philippi Jr., A. \& Ruschmann, D. V. M. (Org.). (2010). Gestão Ambiental e Sustentabilidade no Turismo (Coleção Ambiental, v. 9). Barueri, SP: Manole.

Ganem, R. S. (Org.). (2010). Conservação da biodiversidade: legislação e políticas públicas (Série memória e análise de leis, n. 2). Brasília: Câmara dos Deputados.

Giatti, L. L. (2004). Ecoturismo e impactos ambientais da região de Iporanga: Vale do RibeiraSão Paulo. São Paulo, 225 p. Tese (Doutorado) Faculdade de Saúde Pública, Universidade de São Paulo.

Hill, J. L. \& Hill, R. A. (2011). Ecotourism in Amazonian Peru: uniting tourism, conservation and community development. Geography, 96:75-85. Recuperado em 22 abril, 2017, de http://www.bristolga.org.uk/files/2015/02/HillHill_Ecotourism_Geography_2011.pdf.

ICMBio. (2011). Avaliação comparada das aplicações do método Rappam nas unidades de conservação federais, nos ciclos 2005-06 e 2010. Instituto Chico Mendes de Conservação da Biodiversidade, WWF-Brasil. Brasília: ICMBio. Recuperado em 29 outubro, 2016, de http://www.icmbio.gov.br/portal/images/sto- ries/comunicacao/downloads/relatrio\%20rappam\%202005\%20x\%202010\%20-

\%20verso\%20integral.pdf

ICMBio .(2016). Crescimento da visitação nos Parques Nacionais, Visitantes UCs 2007 a 2015, Ranking visitantes Parques Nacionais 2012 a 2015 e Ranking visitantes UCs 2012 a 2015. Recuperado em 29 outubro, 2016, de http://www.icmbio.gov.br/portal/images/stories/o-que-fazemos/Dados_de_visita\%C3\%A7\%C3\%A3o_ICMBio-2007-2015.pdf

Instituto Estadual de Florestas. (2015). Plano Emergencial de Uso Público do Parque Estadual da Lapa Grande, Montes Claros, MG. Recuperado em 10 novembro, 2016, de file:///C:/Users/Usu\%C3\%A1rio/Downloads/Item_8.2_Plano_Emergencial_Lapa_Grande_parte_2\%20(2).pdf

Instrução Normativa ICMBio n. 08, de 18 de setembro de 2008 (2008). Estabelece normas e procedimentos para a prestação de serviços vinculados à visitação e ao turismo em Unidades de Conservação Federais por condutores de visitantes. Instituto Chico Mendes de Conservação da Biodiversidade, Brasília, DF. Recuperado em 07 julho, 2016, de http://www.icmbio.gov.br/portal/images/stories/o-que-somos/in082008.pdf.

Instrução Normativa ICMBio n. 02, de 03 de maio de 2016 (2016). Dispõe sobre normas e procedimentos administrativos para autorização de uso para a prestação do serviço de condução de visitantes em unidades de conservação federais, conforme as informações contidas no processo $n^{\circ}$ 02070.001887/2012-05. Instituto Chico Mendes de Conservação da Biodiversidade, Brasília, DF. Recuperado em 07 julho, 2016, de http://www.icmbio.gov.br/cepsul/images/stories/legislacao/Instrucao_normativa/2016/in_icmbio_2_2016_exerc\%C3\%ADcio_atividade_conducaovisitantes_ucs.pdf

Koens, J. F., Dieperink, C. \& Miranda, M. (2009). Ecotourism as a development strategy: experiences from Costa Rica. Environ Dev Sustain 
(2009) 11:1225-1237, 2009. Recuperado em 22 abril, 2017, de

http://www.icmyl.unam.mx/pdf/GRAMED/Assessments_Delivery-Item-1/New\%20Assessments/New_Assessments_pdf_support\%20information/Ecotourism\%20as\%20a\%20development\%20strategy.pdf.

Lei no. 8.623, de 28 de janeiro de 1993 (1993). Dispõe sobre a profissão de Guia de Turismo e dá outras providências. Diário Oficial da União, Brasília, 1993. Recuperado em 29 outubro, 2016, de http://www.planalto.gov.br/ccivil_03/LEIS/L8623.htm

Lei n. 9.985, de 18 de julho de 2000 (2000). Institui o Sistema Nacional de Unidades de Conservação da Natureza e dá outras providências. Brasília, DF. Recuperado em 17 outubro, 2014, de https://www.planalto.gov.br/ccivil_03/leis/l9985.htm .

Martha, M. (2012). Tourism and the Galápagos Islands: Examining the Relationship Between Ecotourism and the Local Population. Hofstra University. Recuperado em 22 abril, 2017, de https://www.hofstra.edu/pdf/academics/colleges/hclas/geog/geog_honors_martha.pdf.

Medeiros, R. \& Young, C. E. F. (2011). Contribuição das unidades de conservação brasileiras para a economia nacional (Relatório Final). Brasília: UNEP-WCMC. Recuperado em 07 julho, 2016, de http://www.mma.gov.br/estruturas/240/_arquivos/relatorio_final_contribuio_uc_para_a_economia_nacional_reduzido_240.pdf

Medeiros, R. \& Pereira, G. S. (2011). Evolução e implementação dos planos de manejo em parques nacionais no estado do Rio de Janeiro. $R e-$ vista Árvore, Viçosa-MG, v.35, n.2, p.279-288, 2011. Recuperado em 29 outubro, 2016, de http://www.scielo.br/pdf/rarv/v35n2/a12v35n2.pdf

Ministério do Meio Ambiente. (2005). Diagnóstico da visitação em parques nacionais e estaduais.
Brasília: MMA. Recuperado em 07 julho, 2016, de http://www.mma.gov.br/estruturas/sbs_dap/_arquivos/diagnostico_da_visitacao_em_parque

Ministério do Meio Ambiente. (2006). Diretrizes para a visitação em unidades de conservação. Brasília: MMA. Recuperado em 07 julho, 2016, de http://www.mma.gov.br/estruturas/ascom_boletins/_arquivos/livro.pdf

Ministério do Trabalho. (2011). O que é economia Solidária. Ministério do TrabalhoBrasil. Recuperado em 29 outubro, 2016, de <http://www.mte.gov.br/ecosolidaria/ecosolida ria_oque.asp $>$

Ministério do Turismo. (2010). Segmentação do Turismo e o Mercado. Brasília: Ministério do Turismo, 2010. Recuperado em 29 outubro, 2016, de http://www.turismo.gov.br/sites/default/turismo/o_ministerio/publicacoes/downloads_publicacoes/Segmentaxo_do_Mercado_Versxo_Final_IMPRESSXO_.pdf

Nascimento, C. A., Canto-Silva, C. R. C., Melo, I. B. N. \& Marques, S. C. M. (2016). A regulamentação da atividade de condução de visitantes nos Sistemas Estaduais de Unidades de Conservação do Brasil. Revista Brasileira de Pesquisa em Turismo, v. 10, p. 516-532. Recuperado em 29 outubro, 2016, de https://www.rbtur.org/rbtur/article/viewFile/1133/723.

Passold, A. J. \& Kinker, S. M. S. (2010). Visitação Sustentável em Unidades de Conservação. In Philippi Jr., A. \& Ruschmann, D. V. M. (Org.). (2010). Gestão Ambiental e Sustentabilidade no Turismo (Coleção Ambiental, v. 9). Barueri, SP: Manole.

Pisciotta, k. (1994). Educação Ambiental. In: Fundação para Conservação e a Produção Florestal do Estado de São Paulo. Intervales. São Paulo: A Fundação, p. 37-44.

Portaria do Ministério do Turismo n. 27 de 30 de janeiro de 2014 (2014). Estabelece requisitos e critérios para o exercício da atividade de Guia de 
Turismo e dá outras providências. Diário Oficial da União, Brasília. Recuperado em 07julho, 2016, de http://www.turismo.gov.br/legisla$\mathrm{cao} / \mathrm{p}=117$

Ribas, L. C. C. \& Hickenbick, C. (2012I). O Papel de condutores ambientais locais e de cursos de capacitação no ecodesenvolvimento turístico e as expectativas sociais no sul do Brasil. Turismo em Análise, 23(1), 143-165. Recuperado em 07julho, 2016, de http://www.revistas.usp.br/rta/article/view/52415/56409.

Ruschmann, D. (2006). Turismo e planejamento sustentável: a proteção do meio ambiente. 13. ed. São Paulo: Papirus.

Silva, E. M. da, Gonçalves, V. \& Murolo, A. C. (1997). Estatística para os cursos de Economia, Administração e Ciências Contábeis. São Paulo, Editora Atlas, v. 2.

Silveira, A. R. M. (1997). Vila São Jorge \& Parque Nacional da Chapada dos Veadeiros: o impacto cultural de um projeto ecológico. Brasília (Série Antropologia). Recuperado em 22abril, 2017, de
http://www.dan.unb.br/images/doc/Serie214empdf.pdf.

Vallejo, L. R. (2013). Uso público em áreas protegidas: atores, impactos, diretrizes de planejamento e gestão. Revista Eletrônica Anais Uso Público em Unidades de Conservação, 1(1), 13-26. Recuperado em 17 outubro, 2014, de http://www.uff.br/var/www/htdocs/usopublico/images/Artigos/2013/Artigo_OL_2.pdf.

Dados dos autores

\section{Celson Roberto Canto Silva}

Mestre em Ecologia e doutor em Biologia Animal pela Universidade Federal do Rio Grande do Sul. Professor da Área de Ciências Biológicas e Ciências Ambientais do Instituto Federal de Educação, Ciência e Tecnologia do Rio Grande do Sul, Campus Porto Alegre. Email: celson.silva@poa.ifrs.edu.br

\section{Jordana dos Santos Silva}

Graduada em Tecnologia em Gestão Ambiental pelo Instituto Federal de Educação, Ciência e Tecnologia do Rio Grande do Sul, Campus Porto Alegre. Email: sansil.estudos@gmail.com 